\title{
Epidermal Growth Factor and Intestinal Barrier Function
}

\author{
Xiaopeng Tang, ${ }^{1,2}$ Hu Liu, ${ }^{1,2}$ Shufen Yang, ${ }^{1,2}$ Zuohua Li, ${ }^{1,2}$ \\ Jinfeng Zhong, ${ }^{1,2,3}$ and Rejun Fang ${ }^{1,2}$ \\ ${ }^{1}$ College of Animal Science and Technology, Hunan Agricultural University, Changsha 410128, China \\ ${ }^{2}$ Hunan Co-Innovation Center of Animal Production Safety, Changsha 410128, China \\ ${ }^{3}$ Hunan Polytechnic of Environment and Biology, Hengyang 421005, China
}

Correspondence should be addressed to Rejun Fang; fangrj63@126.com

Received 5 April 2016; Accepted 26 June 2016

Academic Editor: Dianne Cooper

Copyright (C) 2016 Xiaopeng Tang et al. This is an open access article distributed under the Creative Commons Attribution License, which permits unrestricted use, distribution, and reproduction in any medium, provided the original work is properly cited.

\begin{abstract}
Epidermal growth factor (EGF) is a 53-amino acid peptide that plays an important role in regulating cell growth, survival, migration, apoptosis, proliferation, and differentiation. In addition, EGF has been established to be an effective intestinal regulator helping to protect intestinal barrier integrity, which was essential for the absorption of nutrients and health in humans and animals. Several researches have demonstrated that EGF via binding to the EGF receptor and subsequent activation of Ras/MAPK, PI3K/AKT, PLC$\gamma / \mathrm{PKC}$, and STATS signal pathways regulates intestinal barrier function. In this review, the relationship between epidermal growth factor and intestinal development and intestinal barrier is described, to provide a better understanding of the effects of EGF on intestine development and health.
\end{abstract}

\section{Introduction}

In addition to serving as a major organ for nutrient digestion and absorption, the single layer of intestinal epithelium lining the gut acts as a selective barrier to prevent the passing of toxins, allergens, and pathogens from the luminal content into the circulation system and other tissues [1]. Dysfunction of the intestinal barrier is associated with increased gut permeability and development of multiple gastrointestinal diseases, such as food allergy, inflammatory bowel disease (IBD), irritable bowel syndrome (IBS), celiac disease, and infectious enterocolitis [2-4]. Recently, several substances, such as glutamine [2], sodium butyrate [5], bile acid [6], lactic acid bacteria [7], and epidermal growth factor (EGF) [8,9], have been reported to have a protective effect on intestinal epithelial through various underlying mechanisms.

EGF was first discovered by Dr. Cohen more than half a century ago [10]. It is a cytoprotective peptide consisting of 53 amino acid residues and three intramolecular disulfide bridges which has been detected in a variety of body fluids, such as saliva, milk, amniotic fluid, urine, plasma, and intestinal fluid, which is produced and secreted by the submaxillary salivary glands, mammary glands, placenta, kidney, and duodenal Brunner's glands, respectively [11]. EGF plays an important role in regulating cell growth, survival, migration, apoptosis, proliferation, and differentiation [1216]. In additional to enhancing cellular proliferation and differentiation, EGF also functions as a gastrointestinal tract (GI) mucosal protective factor, which associates with intestinal maturation and maintenance of epithelial cell homeostasis in the small intestine [17]. The biological actions of EGF are mediated via binding to the EGF receptor (EGFR), a transmembrane receptor tyrosine kinase of the ErbB family, that leads to autophosphorylation of receptor tyrosine kinase (RTK) and subsequent activation of Ras/mitogenactivated protein kinases (Ras/MAPK), phosphatidylinositol 3-kinase/AKT (PI3K/AKT), phospholipase C- $\gamma$ /protein kinase C (PLC- $\gamma /$ PKC), and STATS signal pathways [18], to promote intestinal development $[15,19-22]$, regulate tight junction protein expression [9,23-25], reduce cell autophagy [26], inhibit apoptosis induced by oxidative stress [16], and reduce the colonization of the intestinal epithelium by enteropathogens $[8,27-30]$. 
TABLE 1: The applications of EGF for animals on intestinal development.

\begin{tabular}{|c|c|c|c|}
\hline Animal & Dose & Significant results & Reference \\
\hline Fetal rabbit & $300 \mu \mathrm{g} / \mathrm{kg} / \mathrm{d}$ & $\begin{array}{l}\text { EGF infusion significantly increased intrauterine } \\
\text { growth retardation, fetal small intestinal villus height, } \\
\text { and crypt cells }\end{array}$ & {$[35]$} \\
\hline Early-weaned pigs & $1.5 \mathrm{mg} / \mathrm{kg}$ & $\begin{array}{l}\text { Increased the mucosa IgA levels and crypt depth at } \\
\text { jejunum on day } 28 \text { after weaning }\end{array}$ & {$[36]$} \\
\hline Early-weaned mice & $50 \mu \mathrm{g} / \mathrm{kg}$ & $\begin{array}{l}\text { Increased mean villous height and crypt depth and } \\
\text { enhanced enterocyte proliferation }\end{array}$ & {$[37]$} \\
\hline $\begin{array}{l}\text { 1-day-old, large } \\
\text { white-duroc cross } \\
\text { breed piglets }\end{array}$ & $10 \mu \mathrm{g} / \mathrm{kg} / \mathrm{d}$ & $\begin{array}{l}\text { Stimulates proliferation of intestinal crypt epithelial } \\
\text { cells and promotes recovery from atrophic enteritis in } \\
\text { PEDV-infected piglets }\end{array}$ & {$[49]$} \\
\hline Early-weaned pigs & $1.0 \mathrm{mg} / \mathrm{kg}$ diet & $\begin{array}{l}\text { Failed to alter the small intestinal villus morphology, } \\
\text { DNA, or protein content of gastrointestinal mucosa }\end{array}$ & {$[19]$} \\
\hline Early-weaned pigs & $50 \mu \mathrm{g} / \mathrm{kg} \mathrm{BW} / \mathrm{d}$ & $\begin{array}{l}\text { Greater jejunal and duodenal villus heights; greater } \\
\text { intestinal length }\end{array}$ & {$[20]$} \\
\hline Early-weaned pigs & $180 \mu \mathrm{g} / \mathrm{d}$ & $\begin{array}{l}\text { Increased villous height in the duodenum, jejunum, } \\
\text { and ileum }\end{array}$ & {$[21]$} \\
\hline Early-weaned pigs & $115 \mu \mathrm{g} / \mathrm{kg} \mathrm{BW} / \mathrm{d}$ & $\begin{array}{l}\text { Enhanced jejunal structure development, increased villi } \\
\text { height, and decreased lamina propria width }\end{array}$ & {$[15]$} \\
\hline Early-weaned pigs & $180 \mu \mathrm{g} / \mathrm{d}$ & $\begin{array}{l}\text { Increased villus height and increased the intestinal } \\
\text { structural integrity proteins expression }\end{array}$ & {$[22]$} \\
\hline Early-weaned pigs & $60 \mu \mathrm{g} / \mathrm{kg} \mathrm{BW} / \mathrm{d}$ & $\begin{array}{l}\text { Enhanced mean villous height, crypt depth, and villous } \\
\text { height: crypt depth and stimulated proliferation of } \\
\text { piglet enterocytes }\end{array}$ & {$[38]$} \\
\hline Early-weaned rats & $50 \mu \mathrm{g} / \mathrm{kg}$ & $\begin{array}{l}\text { Enhanced mean villous height, crypt depth, total } \\
\text { protein, DNA, and RNA and stimulated enterocytes } \\
\text { proliferation }\end{array}$ & {$[39]$} \\
\hline
\end{tabular}

\section{EGF and Intestinal Development}

EGF is acid- and heat-stable and resistant to proteases digestion; it can be administered orogastrically and delivered to the brush border of the small intestine segment where EGFR is abundantly located on both the apical and basolateral aspect of villus enterocytes [31]. The binding of EGF at the enterocytes surface induces dimerization of EGFR, which results in activation of EGFR tyrosine kinase activity and RTK autophosphorylation and subsequent activation of various signal transduction pathways leading to cellular proliferation and differentiation that help in intestinal development and intestinal mucosa repair $[32,33]$. EGF is one of the most abundant growth factors in the milk, more than 500 times higher than other growth factors such as amphiregulin and TGF- $\alpha$ detected in human colostrums [34], indicating an important function EGF performed in early intestinal development. Previous evidence has indicated that EGF plays a significant role in intestinal development, including increasing villous height and crypt depth, enhancing enterocyte proliferation, and stimulating secretion of digestive enzymes such as trypsin, chymotrypsin, alkaline phosphatase, sucrase, maltase, and lactase, which is important for improving nutrition absorption, feed utilization, and growth performance of animals [15, 19-22, 35-39]. The applications of EGF for animals are listed in Table 1.
The intestinal development is related to the intestinal barrier integrity directly, to keep intestinal health, and intracellular homeostasis is essential for the formation of the intestinal barrier. Pervious study has shown EGF controlling mucosal homeostasis through regulating the tight junction components $[9,40]$, enhancing the mucins secretion $[41,42]$, and decreasing pathogens colonization $[8,27-30]$.

\section{EGF and Intestinal Barrier}

3.1. Intestinal Barrier Structure. The intestinal epithelium is formed by a continuous monolayer of proliferating and differentiating intestinal epithelial cells (IECs) separating the intestinal mucosa from the lumen environment. The IECs are tightly bound together by junctional complexes (including tight junctions, gap junctions, adherens junctions, and desmosomes $[43,44])$, which form a selective barrier that allows nutrients absorption and defends against toxins, allergens, and pathogens from the gut lumen into mucosal tissue and circulation [45]. Tight junctions (TJs) seal the space between adjacent epithelial cells near the apical surface, which are the most apical components of intercellular junctional complexes [44, 46]. Adherens junctions (AJs) are located beneath the TJs and are involved in cell-cell adhesion, intracellular signaling, and the integrity of TJs regulation [24, 


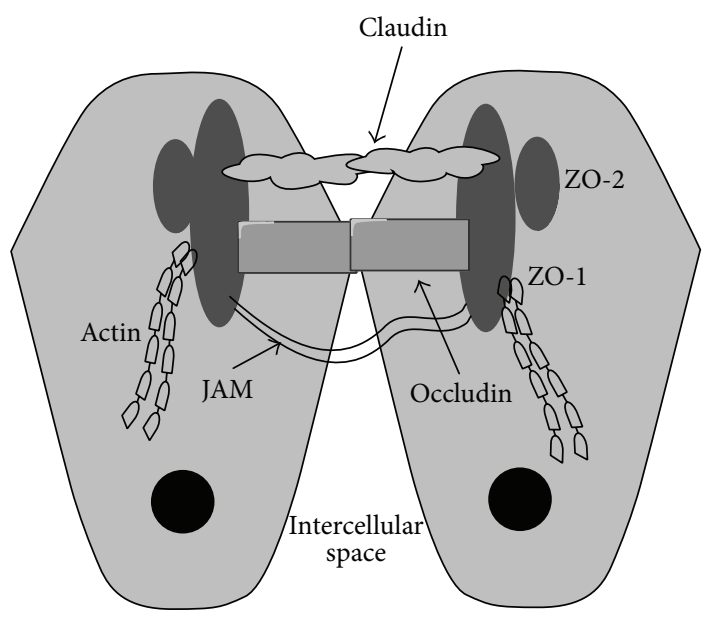

Figure 1: Tight junction structures. The tight junction is organized by multiple transmembrane proteins, including junctional adhesion molecules (JAM), occludin, claudins, and zona occludens (ZO), which interact in a coordinated manner to form intestinal barriers.

$44,46,47]$. Gap junctions and desmosomes contribute to cellcell adhesion and intracellular communication, respectively $[44,46]$. Disruption of the intercellular junctional complex has been reported to increase intestinal permeability that results in an easy passing of pathogens into intestinal mucosa which causes numerous gastrointestinal diseases [44, 48]. Thus, maintaining the integrity of intercellular junctional complex is critical for intestinal development and health.

3.2. Regulation of Tight Junction by EGF. TJs are multiple protein complexes composed of at least three types of transmembrane proteins, claudins, occludin, and junctional adhesion molecule (JAM), which interact with cytoplasmic scaffold protein such as zona occludens (ZO-1, ZO-2, and ZO-3) and interact in a coordinated manner to form intestinal barriers (Figure 1) [61, 62]. They regulate the paracellular passage of ions, water, and solutes and act as a fence to maintain cell polarity by blocking the free diffusion of proteins and lipids between the apical and basolateral domains of the plasma membrane [62]. Significant evidences indicate that TJs are associated with numerous intracellular signaling molecules regulated by the activity of signal transduction pathways [23]. The integrity of the TJ is regulated by PKC, PI3K, MAPK, myosin light chain kinase (MLCK), the Rho family of small GTPases, G-proteins, c-Src, PLC- $\gamma$, and protein phosphatase 2A (PP2A) [23, 46, 63].

EGF is a key regulator of epithelial paracellular permeability, a property that depends on TJs and can be evaluated through the measurement of the transepithelial electrical resistance (TER) [23-25]. EGF has been shown to protect intestinal barrier function by preventing early-weaned [22], hydrogen peroxide [40,50-52], ethanol [8], acetaldehyde [53-55], and intestinal ischemia-reperfusion $[16,64]$ induced disruption of TJs and paracellular permeability. EGF induces changes in the composition of TJ through activating several signaling pathways such as PKC [50], MAPK [23], and STATs [25] in different types of cells (Table 2).

Numerous researches have demonstrated that oxidative stress impairs intestinal barrier function [65]. Weaning pigs from the sows is one of the most stressful events in the pig's life that can contribute to intestinal dysfunctions [66]. $\mathrm{Xu}$ et al. [22] indicated that the oral administration of EGF could improve the gene expression of tight junction proteins such as ZO-1, claudin-1, and occludin, thus enhancing the intestinal barrier function of early-weaned piglets. EGF prevented hydrogen peroxide-induced intestinal barrier disruption through ERK/MAPK and PLC/PKC pathways (Figure 2). Basuroy et al. [23] showed that, in Caco-2 cells, pretreating with EGF can inhibit the oxidative stress-induced intestinal barrier disruption, as indicated by TER, and TJ proteins (ZO-1 and occludin) redistribution, while pretreatment of Caco-2 cells with MAPK/ERK kinase (MEK) inhibitors completely blocked the protective effects of EGF on TJs. When epithelial cells suffered from stress, upon supplementation with EGF they bind to EGFR, leading to autophosphorylation of RTK; the interaction between EGFR and SHC/Grb2 results in the recruitment of SOS to the plasma membrane to activate Ras. Activated Ras mediates Raf activation and then activates MEK, leading to the activation of ERKs [18, 33]. Activated ERK can regulate the expression of TJs such as ZO-1, occludin, and claudin (Figure 2). Pretreating with EGF can increase F-actin expression, decrease G-actin expression [40], and increase the F-actin-to-G-actin ratio [52]. EGF protection against oxidants requires PKC (isoforms $\beta 1$ and $\xi)$ activation $[50,51]$; the activation of PLC $-\gamma /$ PKC- $\beta 1$ can inhibit the activation of NF- $\kappa \mathrm{B}$ and enhance $\mathrm{I} \kappa \mathrm{B} \alpha$ stabilization, which helps to protect the F-actin assembly and barrier function in enterocyte monolayers [40, 52]. Arda-Pirincci and Bolkent [16] reported that EGF treatment of rats with ischemia-reperfusion prevented the ischemia/reperfusioninduced oxidative injury by reducing apoptosis and lipid peroxidation and by increasing antioxidant enzyme activities. Geng et al. [64] showed that the TJs (ZO-1 and occludin) in jejunum and ileum are notably accelerated and expressed in all EGF-treated ischemia-reperfusion rats. Ethanol and its oxidized metabolite, acetaldehyde, also induce intestinal hyperpermeability, which contributes to the development of alcoholic liver disease (ALD) [62]. Banan et al. [67] showed 
TABLE 2: The effects of EGF on EGF-mediated protection of tight junctions.

\begin{tabular}{|c|c|c|c|c|}
\hline Cell lines & Inducer & TJ associated proteins & Involved pathways & Reference \\
\hline Caco-2 & Hydrogen peroxide & $\begin{array}{l}\text { Increased in tubulin } \\
\text { polymerization }\end{array}$ & PKC- $\beta 1$ & {$[50]$} \\
\hline Caco-2 & Hydrogen peroxide & $\begin{array}{l}\text { Increased in tubulin } \\
\text { polymerization and decreased } \\
\text { in monomeric tubulin }\end{array}$ & PKC- $\xi$ & {$[51]$} \\
\hline Caco-2 & Hydrogen peroxide & $\begin{array}{l}\text { Increased F-actin-to-G-actin } \\
\text { ratio }\end{array}$ & PKC- $\beta 1 \uparrow ; \mathrm{NF}-\kappa \mathrm{B} \downarrow^{2}$ & {$[52]$} \\
\hline Caco-2 & Acetaldehyde & Occludin $\uparrow ; Z \mathrm{ZO}-1 \uparrow^{1}$ & $\begin{array}{l}\text { Inhibited tyrosine } \\
\text { phosphorylation }\end{array}$ & {$[53]$} \\
\hline Caco-2 & Hydrogen peroxide & F-actin $\uparrow$; G-actin $\downarrow$ & PLC- $\gamma \uparrow ;$ NF- $\kappa$ B $\downarrow$ & {$[40]$} \\
\hline Caco-2 & Hydrogen peroxide & Occludin $\uparrow ; \mathrm{ZO}-1 \uparrow$ & ERK-MAPK & {$[23]$} \\
\hline Caco-2 & Acetaldehyde & Occludin $\uparrow ; \mathrm{ZO}-1 \uparrow$ & Not mentioned & {$[54]$} \\
\hline Caco-2 & Acetaldehyde & Occludin $\uparrow ; \mathrm{ZO}-1 \uparrow$ & PLC- $\gamma /$ PKC & {$[55]$} \\
\hline Caco-2 & Acetaldehyde & Occludin $\uparrow ; Z \mathrm{ZO}-1 \uparrow$ & ERK1/2-MAPK & {$[24]$} \\
\hline NRC-1 cells ${ }^{3}$ & Hydrogen peroxide & ZO-1 $\uparrow$; claudin-3 $\uparrow$ & PLC- $\gamma /$ PKC & {$[56]$} \\
\hline $\mathrm{MCAS}^{4}$ & \multirow{2}{*}{ None } & Claudin-3 $\downarrow$ & MEK/ERK or & \multirow{2}{*}[57]{} \\
\hline $\mathrm{HUOA}^{5}$ & & Claudin- $4 \downarrow$ & PI3K/Akt & \\
\hline $\mathrm{MDCK}^{6}$ & None & Claudin- $4 \uparrow$ & MEK/ERK & {$[58]$} \\
\hline MDCK & None & Claudin-2 $\downarrow$; claudin- $4 \uparrow$ & Src and STAT3 & {$[25]$} \\
\hline
\end{tabular}

${ }^{1}$ Symbols $\uparrow$ and $\downarrow$ indicate increases and decreases in the protein or mRNA expression, respectively. ${ }^{2}$ Symbols $\uparrow$ and $\downarrow$ stand for activation and inhibition, respectively. ${ }^{3}$ Cholangiocytes. ${ }^{4}$ Mucinous cystadenocarcinoma. ${ }^{5}$ Serous cystadenocarcinoma. ${ }^{6}$ Darby canine kidney cells.

that ethanol induces disruption of the F-actin cytoskeleton and of intestinal barrier integrity, in part, through I$\mathrm{kBa}$ degradation and NF-kB activation. Chen et al. [8] demonstrated that EGF improved the intestinal integrity by lowering intestinal permeability under chronic ethanol exposure. However, whether EGF protects intestinal barrier function through preventing ethanol-induced disruption of TJs and paracellular permeability has not been reported yet. Acetaldehyde, a metabolic product of ethanol oxidation, seriously harms the intestinal barrier function. Previous studies have shown that acetaldehyde, but not ethanol, disrupts TJ and increases paracellular permeability by a tyrosine kinase-dependent mechanism $[24,54,55]$. Acetaldehyde induces tyrosine phosphorylation of occludin, ZO-1, E-cadherin, and $\beta$-catenin and dissociates these proteins from the actin-rich, detergent-insoluble fractions [24, 53-55]. EGF prevents acetaldehyde-induced increase in paracellular permeability (as indicated by increased TER and decreased macromolecule flux) and redistribution of occludin, ZO-1, E-cadherin, and $\beta$-catenin from the intercellular junctions through the activation of EGFR-PLC- $\gamma$-PKC $\beta 1 / \epsilon$ and EGFRERK/MAPK signaling pathways (Figure 2) [24, 55].

Previous studies indicated that EGF has a potential role in the prevention of necrotizing enterocolitis- (NEC-) induced TJs disruption in neonates, including humans and rats [68, 69]. Clark et al. [41] showed that NEC rats supplemented with EGF can make the expression of occludin and claudin-3 in the ileum normalized, which help to maintain intestinal barrier function.

3.3. EGF Promotes Mucin Secretion. The intestinal epithelial monolayer also protects and separates itself physically from exogenous stress by secreting mucins to form a thick protective layer of mucus over the intestinal mucosas which are important for intestinal lubrication, limiting bacteria adhesion and maintaining proper intestinal permeability [15, 70]. Mucins (Muc), both secretory type (including Muc2, Muc5AC, Muc5B, Muc6, and Muc19) and membrane-bound type (including Muc1, Muc3, Muc4, Muc12, Muc13, Muc15, Muc16, Muc17, and Muc20), are high molecular weight, heavily glycosylated proteins. EGF seems to exert beneficial effects on intestinal mucosas mucin secretion especially Muc2, Muc3, and Muc5AC $[15,42]$. Muc2 is one of the most predominant gel-forming mucins secreted by goblet cells in the small intestine and colon [71]. Muc5AC expressed by goblet cell is mainly present at the inner mucous layer of gastric mucosa [71]. Muc3 is a transmembrane mucin expressed in the small intestine and colon [42, 71]. Clark et al. [41] demonstrated that treatment of NEC with EGF increased goblet cell density and Muc2 production in the ileum but had no effect on Muc2 production in the jejunum. Bedford et al. [15] showed that EGF treatment can increase the expression of interleukin13 (IL-13), stimulating both goblet cell differentiation and mucin secretion in the intestine [72], and keratinocyte growth factor (KGF), stimulating human colonic epithelial cell differentiation into goblet cells [73], that resulted in an increased Muc2 expression. The reactive oxygen species (ROS) generated by the membrane NADPH oxidase (NOXs) enzymes, such as dual oxidases 2 (DUOX2), has shown to contribute to promoting receptor signaling activation [74]. Damiano et al. [42] found that EGF modulates DUOX2 levels through ERK1/2-PKC pathways increasing ROS levels, in turn, inducing gel-forming Muc5AC and the transmembrane Muc3 expression. In conclusion, EGF through 


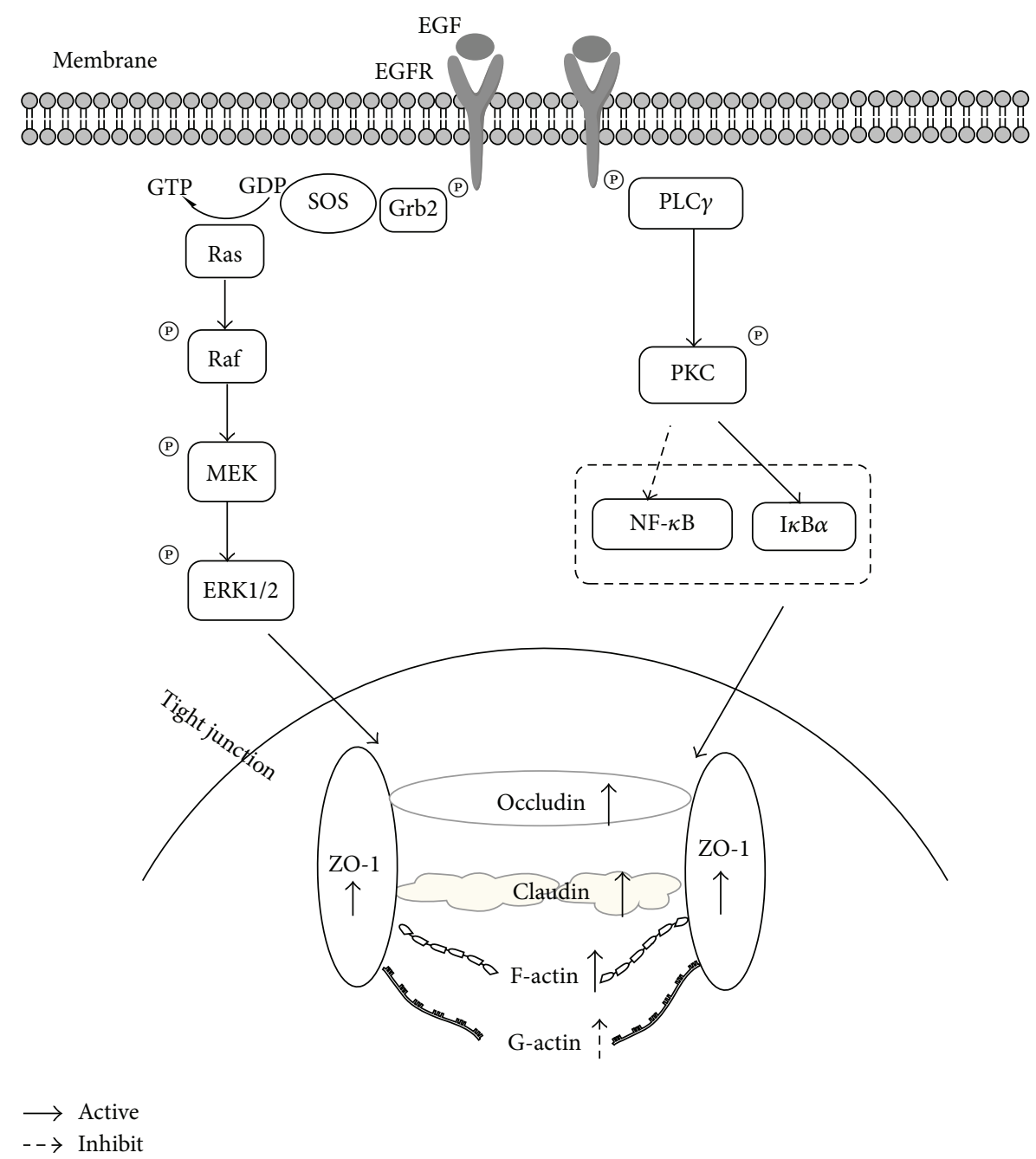

FIGURE 2: The EGFR-phospholipase (PLC)- $\gamma$-PKC and EGFR-ERK/MAPK signaling pathways are involved in EGF-mediated protection of tight junctions. ERK/MAPK pathways were mainly involved in regulating barrier function by improving the gene expression of tight junction proteins such as ZO-1, claudin-1, and occludin, while PLC- $\gamma$-PKC pathways were mainly involved in regulating actin cytoskeletal architecture such as F-actin and G-actin.

stimulating goblet cell differentiation produces Muc2 and through inducing DUOX2 expression and ROS production activates ERK1/2-PKC pathways, thus inducing Muc5AC and Muc3 expression, to form a thick protective layer of mucus over the intestinal mucosas to maintain intestinal 14 barrier integrity (Figure 3 ).

3.4. EGF Reduces Bacterial Colonization. The intestinal microbiota profile plays an essential role in intestinal integrity. EGF can reduce colonization of the intestinal epithelium by enteropathogens, such as Escherichia coli (E. coli) $[21,27,59,60]$, Campylobacter jejuni (C. jejuni) [30], and Enterococcus [21] (Table 3). Administration of EGF to newborn rabbits can significantly reduce bacterial translocation and was associated with increased goblet cells in intestine [59]. Oral administration of EGF to weaned rabbits infected with enteropathogenic E. coli showed a significant inhibition of $E$. coli colonization in the small and large intestine without affecting the proliferation of E. coli in vitro [27]. In addition,
EGF can reduce $C$. jejuni colonization in the jejunum of $C$. jejuni infected chicks and prevent $C$. jejuni-induced claudin4 disruption [30]. What is more, EGF showed a protective effect on TJs in experimental Clostridium difficile (C. difficile) infected mice [9], suggesting a potential role of EGF in reducing $C$. difficile colonization.

\section{Conclusions}

The biological functions of EGF are mediated through binding to EGFR and inducing RTK autophosphorylation and subsequent activation of various signal transduction pathways to regulate intestinal development, TJs expression, and mucins secretion which are important for the formation of intestinal barrier functions. In conclusion, EGF acts as a key epithelial mucosa regulator to regulate intestinal permeability and intestinal barrier integrity through the following 3 ways: (1) activating EGFR-PLC- $\gamma$-PKC and EGFR-ERK/MAPK signaling pathways to regulate TJs expression; (2) stimulating 


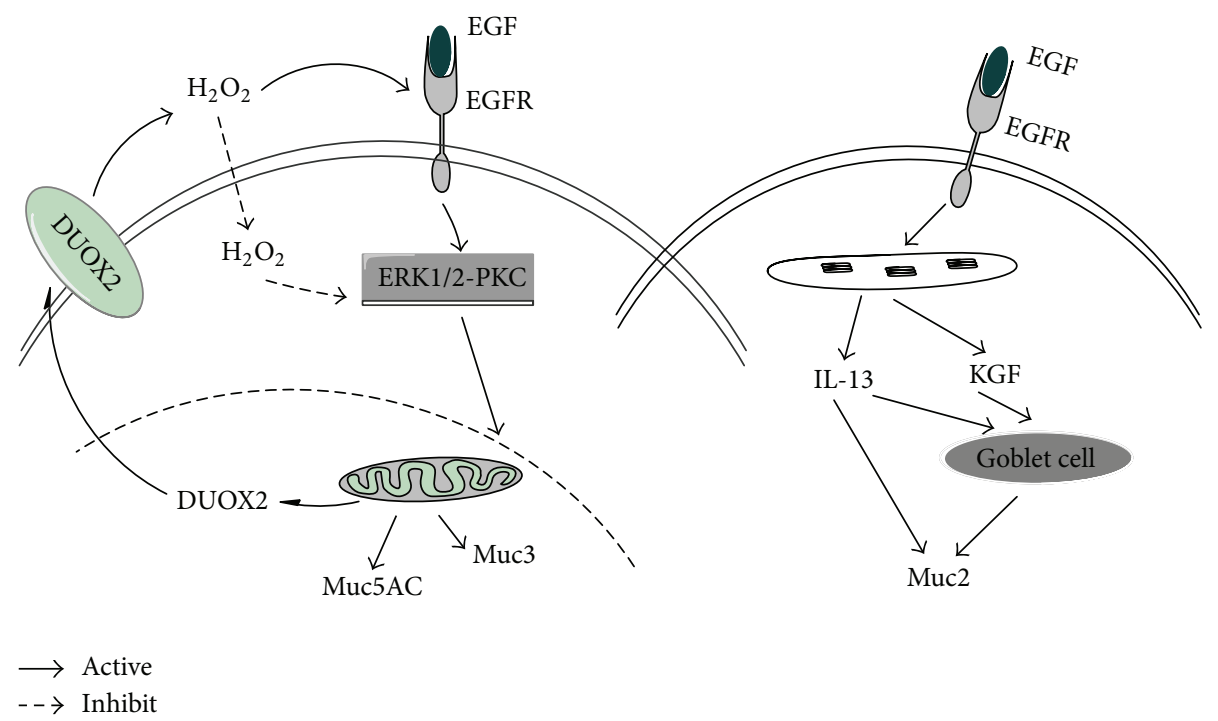

FIGURE 3: Mechanism of EGF induced mucins secretion. EGF treatment can increase the expression of interleukin-13 and keratinocyte growth factor (KGF) that resulted in an increased Muc2 expression [15]. EGF through inducing DUOX2 expression and ROS production to activate ERK1/2-PKC pathways thus inducing Muc5AC and Muc3 expression [42].

TABLE 3: Effects of EGF on intestinal bacterial colonization and translocation.

\begin{tabular}{|c|c|c|}
\hline Animals & Significant results & Reference \\
\hline New Zealand white rabbits & $\begin{array}{l}\text { EGF treatment significantly inhibits enteropathogenic Escherichia coli } \\
\text { colonization in the small and large intestine }\end{array}$ & [27] \\
\hline Newborn rabbits & $\begin{array}{l}\text { Administration of EGF significantly reduced bacterial translocation } \\
\text { and was associated with increased goblet cells in intestine }\end{array}$ & [59] \\
\hline Rats & $\begin{array}{l}\text { Administration of EGF significantly reduced aerobic bacterial } \\
\text { colonization }\end{array}$ & {$[60]$} \\
\hline White leghorn chicks & $\begin{array}{l}\text { EGF reduced Campylobacter jejuni colonization in the jejunum and } \\
\text { dissemination to the liver and spleen and inhibited Escherichia coli } \\
\text { translocation }\end{array}$ & {$[30]$} \\
\hline Rats & $\begin{array}{l}\text { An intervention with EGF decreased fecal Escherichia coli } \\
\text { colonization }\end{array}$ & {$[8]$} \\
\hline Early-weaned piglets & $\begin{array}{l}\text { EGF treatment decreased the amount of Escherichia coli in the ileum } \\
\text { and cecum and Enterococcus counts in the ileum }\end{array}$ & {$[21]$} \\
\hline
\end{tabular}

goblet cell differentiation to produce Muc2 and inducing DUOX2 expression and ROS production to activate ERK1/2PKC pathways thus inducing Muc5AC and Muc3 expression; (3) reducing bacterial colonization and translocation.

\section{Competing Interests}

The authors declare that they have no competing interests.

\section{Acknowledgments}

This work was supported by grants from the National Natural Science Foundation of China (no. 31172218 and no. 31572419) and Hunan Graduate Student Research Innovation Project (no. CX2016B276). The authors also thank Professor Olayiwola Adeola from Purdue University of America for kindly revising this paper.

\section{References}

[1] M. C. Arrieta, L. Bistritz, and J. B. Meddings, "Alterations in intestinal permeability," Gut, vol. 55, no. 10, pp. 1512-1520, 2006.

[2] H. Wang, C. Zhang, G. Wu et al., "Glutamine enhances tight junction protein expression and modulates corticotropinreleasing factor signaling in the jejunum of weanling piglets," The Journal of Nutrition, vol. 145, no. 1, pp. 25-31, 2015.

[3] M. Camilleri, K. Madsen, R. Spiller, B. G. Van Meerveld, and G. N. Verne, "Intestinal barrier function in health and gastrointestinal disease," Neurogastroenterology and Motility, vol. 24, no. 6, pp. 503-512, 2012.

[4] R. K. Rao and G. Samak, "Role of glutamine in protection of intestinal epithelial tight junctions," Journal of Epithelial Biology and Pharmacology, vol. 5, supplement 1, pp. 47-54, 2012.

[5] X. Han, H. Song, Y. Wang, Y. Sheng, and J. Chen, "Sodium butyrate protects the intestinal barrier function in peritonitic 
mice," International Journal of Clinical and Experimental Medicine, vol. 8, no. 3, pp. 4000-4007, 2015.

[6] N. de Diego-Cabero, A. Mereu, D. Menoyo, J. J. Holst, and I. R. Ipharraguerre, "Bile acid mediated effects on gut integrity and performance of early-weaned piglets," BMC Veterinary Research, vol. 11, no. 1, article 111, 2015.

[7] F. Yang, C. Hou, X. Zeng, and S. Qiao, "The use of lactic Acid bacteria as a probiotic in Swine diets," Pathogens, vol. 4, no. 1, pp. 34-45, 2015.

[8] Y.-L. Chen, H.-C. Peng, Y.-C. Hsieh, and S.-C. Yang, "Epidermal growth factor improved alcohol-induced inflammation in rats," Alcohol, vol. 48, no. 7, pp. 701-706, 2014.

[9] S. Kaur, C. Vaishnavi, P. Ray, M. Singh, and R. Kochhar, "Preliminary investigation on the effect of lactobacillus and epidermal growth factor on tight junction proteins in experimental Clostridium difficile infection," Advances in Microbiology, vol. 4, no. 8, pp. 425-435, 2014.

[10] S. Cohen, "Isolation of a mouse submaxillary gland protein accelerating incisor eruption and eyelid opening in the newborn animal," The Journal of Biological Chemistry, vol. 237, pp. 1555-1562, 1962.

[11] H. F. Zeng and R. C. Harris, "Epidermal growth factor, from gene organization to bedside," Seminars in Cell \& Developmental Biology, vol. 28, pp. 2-11, 2014.

[12] P. B. Alexander, L. Yuan, P. Yang et al., "EGF promotes mammalian cell growth by suppressing cellular senescence," Cell Research, vol. 25, no. 1, pp. 135-138, 2015.

[13] A. Iwabu, K. Smith, F. D. Allen, D. A. Lauffenburger, and A. Wells, "Epidermal growth factor induces fibroblast contractility and motility via a protein kinase $\mathrm{C} \delta$-dependent pathway," Journal of Biological Chemistry, vol. 279, no. 15, pp. 14551-14560, 2004.

[14] W. Jeong, J. Kim, F. W. Bazer, and G. Song, "Epidermal growth factor stimulates proliferation and migration of porcine trophectoderm cells through protooncogenic protein kinase 1 and extracellular-signal-regulated kinases $1 / 2$ mitogen-activated protein kinase signal transduction cascades during early pregnancy," Molecular and Cellular Endocrinology, vol. 381, no. 1-2, pp. 302-311, 2013.

[15] A. Bedford, T. Chen, E. Huynh et al., "Epidermal growth factor containing culture supernatant enhances intestine development of early-weaned pigs in vivo: Potential mechanisms involved," Journal of Biotechnology, vol. 196-197, pp. 9-19, 2015.

[16] P. Arda-Pirincci and S. Bolkent, "The role of epidermal growth factor in prevention of oxidative injury and apoptosis induced by intestinal ischemia/reperfusion in rats," Acta Histochemica, vol. 116, no. 1, pp. 167-175, 2014.

[17] G. Duh, N. Mouri, D. Warburton, and D. W. Thomas, "EGF regulates early embryonic mouse gut development in chemically defined organ culture," Pediatric Research, vol. 48, no. 6, pp. 794-802, 2000.

[18] T. M. Brand, M. Iida, C. Li, and D. L. Wheeler, "The nuclear epidermal growth factor receptor signaling network and its role in cancer," Discovery Medicine, vol. 12, no. 66, pp. 419-432, 2011.

[19] D. N. Lee, W. F. Chang, I. T. Yu, P. W. S. Chiou, and C. F. Weng, "Effects of diets supplemented with recombinant epidermal growth factor and glutamine on gastrointestinal tract development of early-weaned piglets," Asian-Australasian Journal of Animal Sciences, vol. 21, no. 4, pp. 582-589, 2008.

[20] P. Kang, D. Toms, Y. Yin et al., "Epidermal growth factorexpressing Lactococcus lactis enhances intestinal development of early-weaned pigs," The Journal of Nutrition, vol. 140, no. 4, pp. 806-811, 2010.

[21] D. Wang, S. Xu, Y. Lin et al., "Recombinant porcine epidermal growth factor-secreting Lactococcus lactis promotes the growth performance of early-weaned piglets," BMC Veterinary Research, vol. 10, no. 1, article 171, 2014.

[22] S. Xu, D. Wang, P. Zhang et al., "Oral administration of Lactococcus lactis-expressed recombinant porcine epidermal growth factor stimulates the development and promotes the health of small intestines in early-weaned piglets," Journal of Applied Microbiology, vol. 119, no. 1, pp. 225-235, 2015.

[23] S. Basuroy, A. Seth, B. Elias, A. P. Naren, and R. Rao, "MAPK interacts with occludin and mediates EGF-induced prevention of tight junction disruption by hydrogen peroxide," Biochemical Journal, vol. 393, no. 1, pp. 69-77, 2006.

[24] G. Samak, S. Aggarwal, and R. K. Rao, "ERK is involved in EGF-mediated protection of tight junctions, but not adherens junctions, in acetaldehyde-treated Caco-2 cell monolayers," American Journal of Physiology-Gastrointestinal and Liver Physiology, vol. 301, no. 1, pp. G50-G59, 2011.

[25] V. García-Hernández, C. Flores-Maldonado, R. RinconHeredia et al., "EGF regulates claudin-2 and -4 expression through Src and STAT3 in MDCK cells," Journal of Cellular Physiology, vol. 230, no. 1, pp. 105-115, 2015.

[26] A. A. Maynard, K. Dvorak, L. Khailova et al., "Epidermal growth factor reduces autophagy in intestinal epithelium and in the rat model of necrotizing enterocolitis," American Journal of Physiology-Gastrointestinal and Liver Physiology, vol. 299, no. 3, pp. G614-G622, 2010.

[27] A. Buret, M. E. Olson, D. Grant Gall, and J. A. Hardin, "Effects of orally administered epidermal growth factor on enteropathogenic Escherichia coli infection in rabbits," Infection and Immunity, vol. 66, no. 10, pp. 4917-4923, 1998.

[28] A. G. Buret, K. Mitchell, D. G. Muench, and K. G. E. Scott, "Giardia lamblia disrupts tight junctional ZO-1 and increases permeability in non-transformed human small intestinal epithelial monolayers: effects of epidermal growth factor," Parasitology, vol. 125, no. 1, pp. 11-19, 2002.

[29] A. G. Buret, A. C. Chin, and K. G. E. Scott, "Infection of human and bovine epithelial cells with Cryptosporidium andersoni induces apoptosis and disrupts tight junctional ZO-1: effects of epidermal growth factor," International Journal for Parasitology, vol. 33, no. 12, pp. 1363-1371, 2003.

[30] J. M. Lamb-Rosteski, L. D. Kalischuk, G. D. Inglis, and A. G. Buret, "Epidermal growth factor inhibits Campylobacter jejuniinduced claudin-4 disruption, loss of epithelial barrier function, and Escherichia coli translocation," Infection and Immunity, vol. 76, no. 8, pp. 3390-3398, 2008.

[31] N. E. Avissar, H. T. Wang, J.-N. H. Miller, P. Iannoli, and H. C. Sax, "Epidermal growth factor receptor is increased in rabbit intestinal brush border membrane after small bowel resection," Digestive Diseases and Sciences, vol. 45, no. 6, pp. 1145-1152, 2000.

[32] J. A. Clark, A. T. Clark, R. S. Hotchkiss, T. G. Buchman, and C. M. Coopersmith, "Epidermal growth factor treatment decreases mortality and is associated with improved gut integrity in sepsis," Shock, vol. 30, no. 1, pp. 36-42, 2008.

[33] P. Wee, H. Shi, J. Jiang, Y. Wang, and Z. Wang, "EGF stimulates the activation of EGF receptors and the selective activation of major signaling pathways during mitosis," Cellular Signalling, vol. 27, no. 3, pp. 638-651, 2015. 
[34] T. Nojiri, T. Yoshizato, T. Fukami et al., "Clinical significance of amphiregulin and epidermal growth factor in colostrum," Archives of Gynecology and Obstetrics, vol. 286, no. 3, pp. 643647, 2012.

[35] C. Cellini, J. Xu, A. Arriaga, and T. L. Buchmiller-Crair, "Effect of epidermal growth factor infusion on fetal rabbit intrauterine growth retardation and small intestinal development," Journal of Pediatric Surgery, vol. 39, no. 6, pp. 891-897, 2004.

[36] D.-N. Lee, T.-Y. Kuo, M.-C. Chen, T.-Y. Tang, F.-H. Liu, and C.-F. Weng, "Expression of porcine epidermal growth factor in Pichia pastoris and its biology activity in early-weaned piglets," Life Sciences, vol. 78, no. 6, pp. 649-654, 2006.

[37] Q. C. K. Cheung, Z. Yuan, P. W. Dyce, De Wu, K. Delange, and J. Li, "Generation of epidermal growth factor-expressing Lactococcus lactis and its enhancement on intestinal development and growth of early-weaned mice," American Journal of Clinical Nutrition, vol. 89, no. 3, pp. 871-879, 2009.

[38] S. Wang, C. Guo, L. Zhou et al., "Comparison of the biological activities of Saccharomyces cerevisiae-expressed intracellular EGF, extracellular EGF, and tagged EGF in early-weaned pigs," Applied Microbiology and Biotechnology, vol. 99, no. 17, pp. 71257135, 2015.

[39] S. Wang, L. Zhou, H. Chen et al., "Analysis of the biological activities of Saccharomyces cerevisiae expressing intracellular EGF, extracellular EGF, and tagged EGF in early-weaned rats," Applied Microbiology and Biotechnology, vol. 99, no. 5, pp. 21792189, 2015.

[40] A. Banan, L. J. Zhang, M. Shaikh, J. Z. Fields, A. Farhadi, and A. Keshavarzian, "Inhibition of oxidant-induced nuclear factor- $\kappa \mathrm{B}$ activation and inhibitory- $\kappa \mathrm{B} \alpha$ degradation and instability of Factin cytoskeletal dynamics and barrier function by epidermal growth factor: key role of phospholipase- $\gamma$ isoform," Journal of Pharmacology and Experimental Therapeutics, vol. 309, no. 1, pp. 356-368, 2004.

[41] J. A. Clark, S. M. Doelle, M. D. Halpern et al., "Intestinal barrier failure during experimental necrotizing enterocolitis: protective effect of EGF treatment," American Journal of Physiology-Gastrointestinal and Liver Physiology, vol. 291, no. 5, pp. G938G949, 2006.

[42] S. Damiano, A. Morano, V. Ucci et al., "Dual oxidase 2 generated reactive oxygen species selectively mediate the induction of mucins by epidermal growth factor in enterocytes," The International Journal of Biochemistry \& Cell Biology, vol. 60, pp. 8-18, 2015.

[43] K. R. Groschwitz and S. P. Hogan, "Intestinal barrier function: molecular regulation and disease pathogenesis," Journal of Allergy and Clinical Immunology, vol. 124, no. 1, pp. 3-20, 2009.

[44] Y.-B. Yu and Y.-Q. Li, "Enteric glial cells and their role in the intestinal epithelial barrier," World Journal of Gastroenterology, vol. 20, no. 32, pp. 11273-11280, 2014.

[45] D. Günzel and A. S. L. Yu, "Claudins and the modulation of tight junction permeability," Physiological Reviews, vol. 93, no. 2, pp. 525-569, 2013.

[46] B. Wang, G. Wu, Z. Zhou et al., "Glutamine and intestinal barrier function," Amino Acids, vol. 47, no. 10, pp. 2143-2154, 2015.

[47] K. Matter and M. S. Balda, "Signalling to and from tight junctions," Nature Reviews Molecular Cell Biology, vol. 4, no. 3, pp. 225-236, 2003.
[48] Y. Chen, D. F. Li, Z. L. Dai et al., “ L-methionine supplementation maintains the integrity and barrier function of the smallintestinal mucosa in post-weaning piglets," Amino Acids, vol. 46, no. 4, pp. 1131-1142, 2014.

[49] K. Jung, B.-K. Kang, J.-Y. Kim, K.-S. Shin, C.-S. Lee, and D.-S. Song, "Effects of epidermal growth factor on atrophic enteritis in piglets induced by experimental porcine epidemic diarrhoea virus," Veterinary Journal, vol. 177, no. 2, pp. 231-235, 2008.

[50] A. Banan, J. Z. Fields, D. A. Talmage, Y. Zhang, and A. Keshavarzian, "PKC- $\beta 1$ mediates EGF protection of microtubules and barrier of intestinal monolayers against oxidants," American Journal of Physiology-Gastrointestinal and Liver Physiology, vol. 281, no. 3, pp. G833-G847, 2001.

[51] A. Banan, J. Z. Fields, D. A. Talmage, L. Zhang, and A. Keshavarzian, "PKC- $\zeta$ is required in EGF protection of microtubules and intestinal barrier integrity against oxidant injury," American Journal of Physiology - Gastrointestinal and Liver Physiology, vol. 282, no. 5, pp. G794-G808, 2002.

[52] A. Banan, L. J. Zhang, A. Farhadi, J. Z. Fields, M. Shaikh, and A. Keshavarzian, "PKC- $\beta 1$ isoform activation is required for EGF-induced NF- $\kappa$ B inactivation and $\mathrm{I} \kappa \mathrm{B} \alpha$ stabilization and protection of F-actin assembly and barrier function in enterocyte monolayers," American Journal of Physiology-Cell Physiology, vol. 286, no. 3, pp. C723-C738, 2004.

[53] S. Basuroy, P. Sheth, C. M. Mansbach, and R. K. Rao, "Acetaldehyde disrupts tight junctions and adherens junctions in human colonic mucosa: protection by EGF and L-glutamine," American Journal of Physiology-Gastrointestinal and Liver Physiology, vol. 289, no. 2, pp. G367-G375, 2005.

[54] P. Sheth, A. Seth, M. Thangavel, S. Basuroy, and R. K. Rao, "Epidermal growth factor prevents acetaldehyde-induced paracellular permeability in Caco-2 cell monolayer," Alcoholism: Clinical and Experimental Research, vol. 28, no. 5, pp. 797-804, 2004.

[55] T. Suzuki, A. Seth, and R. Rao, "Role of phospholipase $C \gamma$ induced activation of protein kinase $\mathrm{C} \epsilon(\mathrm{PKC} \epsilon)$ and $\mathrm{PKC} \beta \mathrm{I}$ in epidermal growth factor-mediated protection of tight junctions from acetaldehyde in Caco-2 cell monolayers," The Journal of Biological Chemistry, vol. 283, pp. 3574-3583, 2008.

[56] S. R. Guntaka, G. Samak, A. Seth, N. F. LaRusso, and R. Rao, "Epidermal growth factor protects the apical junctional complexes from hydrogen peroxide in bile duct epithelium," Laboratory Investigation, vol. 91, no. 9, pp. 1396-1409, 2011.

[57] M. Ogawa, T. Kojima, M. Someya et al., "Epidermal growth factor modulates claudins and tight junctional functions in ovarian cancer cell lines," Histochemistry and Cell Biology, vol. 138, no. 2, pp. 323-338, 2012.

[58] A. Ikari, K. Atomi, A. Takiguchi, Y. Yamazaki, M. Miwa, and J. Sugatani, "Epidermal growth factor increases claudin-4 expression mediated by Sp1 elevation in MDCK cells," Biochemical and Biophysical Research Communications, vol. 384, no. 3, pp. 306$310,2009$.

[59] H. Okuyama, M. Urao, D. Lee, R. A. Drongowski, and A. G. Coran, "The effect of epidermal growth factor on bacterial translocation in newborn rabbits," Journal of Pediatric Surgery, vol. 33, no. 2, pp. 225-228, 1998.

[60] S. N. Elliott, J. L. Wallace, W. McKnight et al., "Bacterial colonization and healing of gastric ulcers: the effects of epidermal growth factor," American Journal of PhysiologyGastrointestinal and Liver Physiology, vol. 278, no. 1, pp. G105G112, 2000. 
[61] C. E. Overgaard, B. L. Daugherty, L. A. Mitchell, and M. Koval, "Claudins: control of barrier function and regulation in response to oxidant stress," Antioxidants and Redox Signaling, vol. 15, no. 5, pp. 1179-1193, 2011.

[62] T. Suzuki, "Regulation of intestinal epithelial permeability by tight junctions," Cellular and Molecular Life Sciences, vol. 70, no. 4, pp. 631-659, 2013.

[63] D. Ulluwishewa, R. C. Anderson, W. C. McNabb, P. J. Moughan, J. M. Wells, and N. C. Roy, "Regulation of tight junction permeability by intestinal bacteria and dietary components," Journal of Nutrition, vol. 141, no. 5, pp. 769-776, 2011.

[64] Y. Geng, J. Li, F. Wang et al., "Epidermal growth factor promotes proliferation and improves restoration after intestinal ischemiareperfusion injury in rats," Inflammation, vol. 36, no. 3, pp. 670679, 2013.

[65] R. Rao, "Oxidative stress-induced disruption of epithelial and endothelial tight junctions," Frontiers in Bioscience, vol. 13, no. 18, pp. 7210-7226, 2008.

[66] J. M. Campbell, J. D. Crenshaw, and J. Polo, "The biological stress of early weaned piglets," Journal of Animal Science and Biotechnology, vol. 4, no. 1, article 19, 2013.

[67] A. Banan, A. Keshavarzian, L. Zhang et al., "NF- $\kappa$ B activation as a key mechanism in ethanol-induced disruption of the Factin cytoskeleton and monolayer barrier integrity in intestinal epithelium," Alcohol, vol. 41, no. 6, pp. 447-460, 2007.

[68] R. R. Nair, B. B. Warner, and B. W. Warner, "Role of Epidermal growth factor and other growth factors in the prevention of necrotizing enterocolitis," Seminars in Perinatology, vol. 32, no. 2, pp. 107-113, 2008.

[69] K. Ludmila, D. Katerina, K. M. Arganbright, C. S. Williams, M. D. Halpern, and D. Bohuslav, "Changes in hepatic cell junctions structure during experimental necrotizing enterocolitis: effect of EGF treatment," Pediatric Research, vol. 66, no. 2, pp. 140$144,2009$.

[70] M. D. Halpern and P. W. Denning, "The role of intestinal epithelial barrier function in the development of NEC," Tissue Barriers, vol. 3, no. 1-2, article e1000707, 2015.

[71] M. E. Johansson, H. Sjövall, and G. C. Hansson, "The gastrointestinal mucus system in health and disease," Nature Reviews Gastroenterology \& Hepatology, vol. 10, no. 6, pp. 352-361, 2013.

[72] P. Mannon and W. Reinisch, "Interleukin 13 and its role in gut defence and inflammation," Gut, vol. 61, no. 12, pp. 1765-1773, 2012.

[73] D. Iwakiri and D. K. Podolsky, "Keratinocyte growth factor promotes goblet cell differentiation through regulation of goblet cell silencer inhibitor," Gastroenterology, vol. 120, no. 6, pp. 1372-1380, 2001.

[74] X. De Deken, B. Corvilain, J. E. Dumont, and F. Miot, "Roles of DUOX-mediated hydrogen peroxide in metabolism, host defense, and signaling," Antioxidants \& Redox Signaling, vol. 20, no. 17, pp. 2776-2793, 2014. 


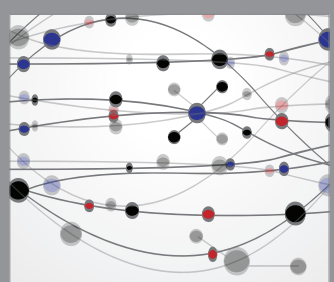

The Scientific World Journal
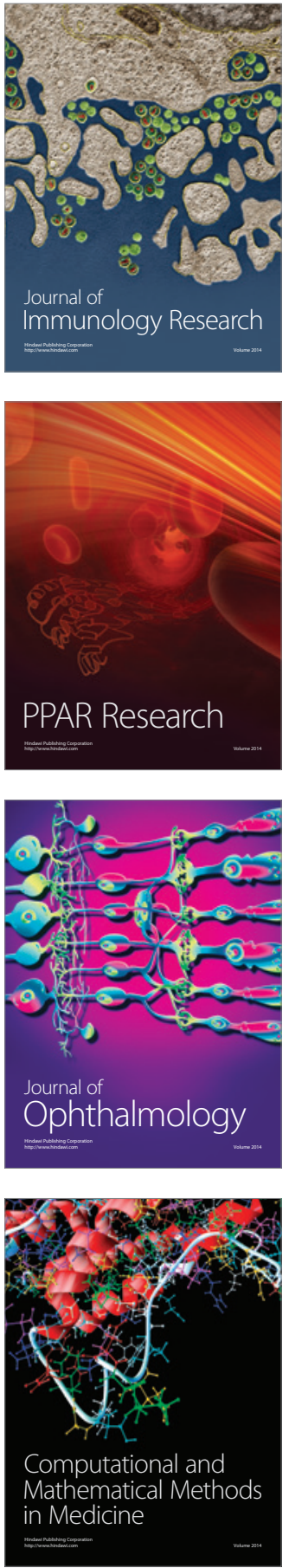

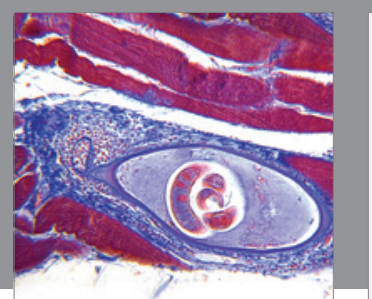

Gastroenterology Research and Practice

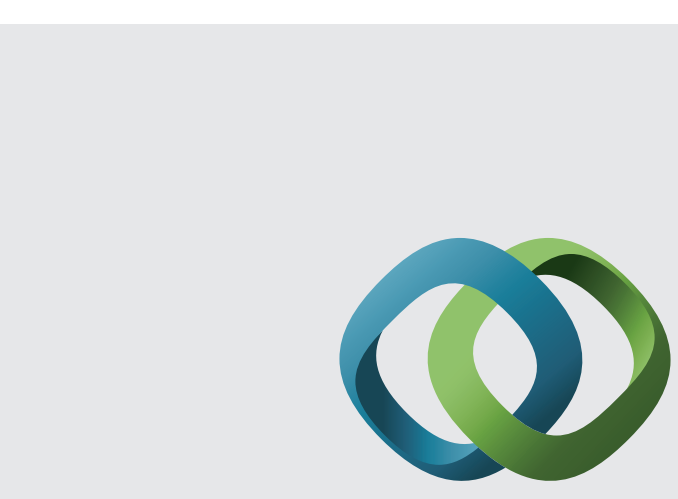

\section{Hindawi}

Submit your manuscripts at

http://www.hindawi.com
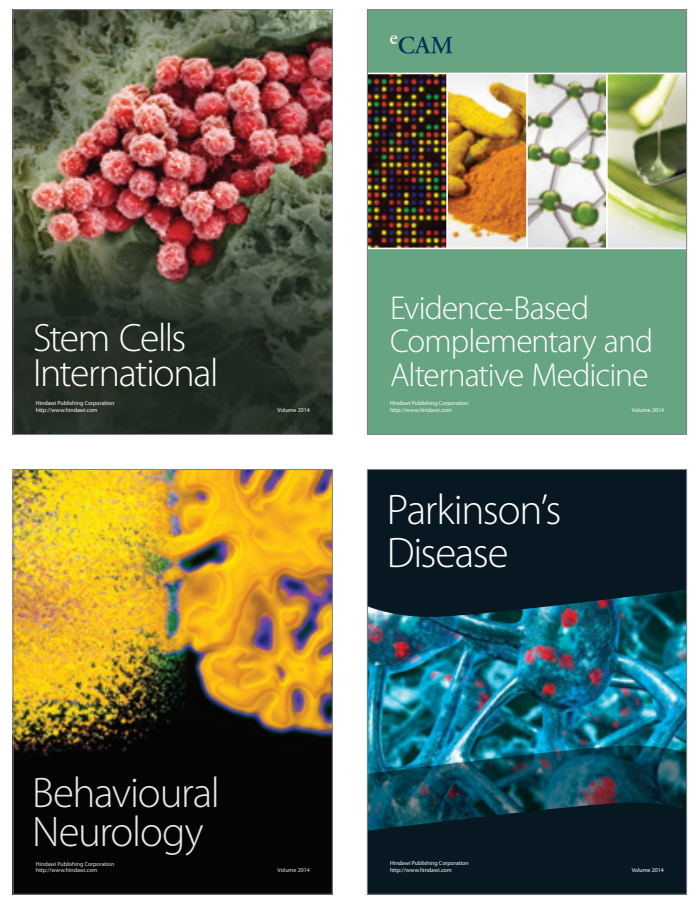
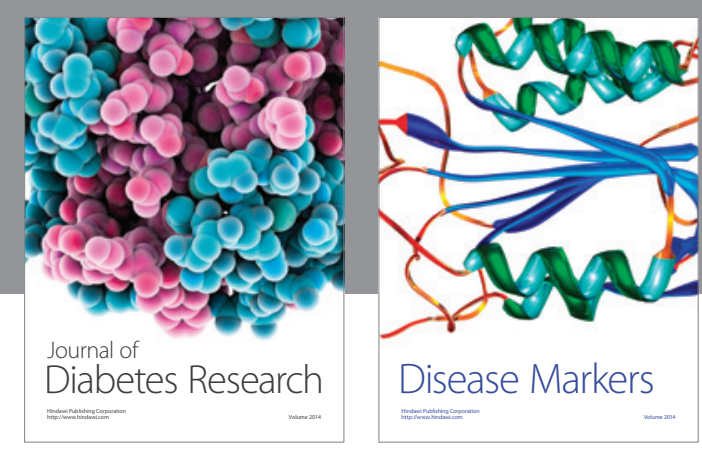

Disease Markers
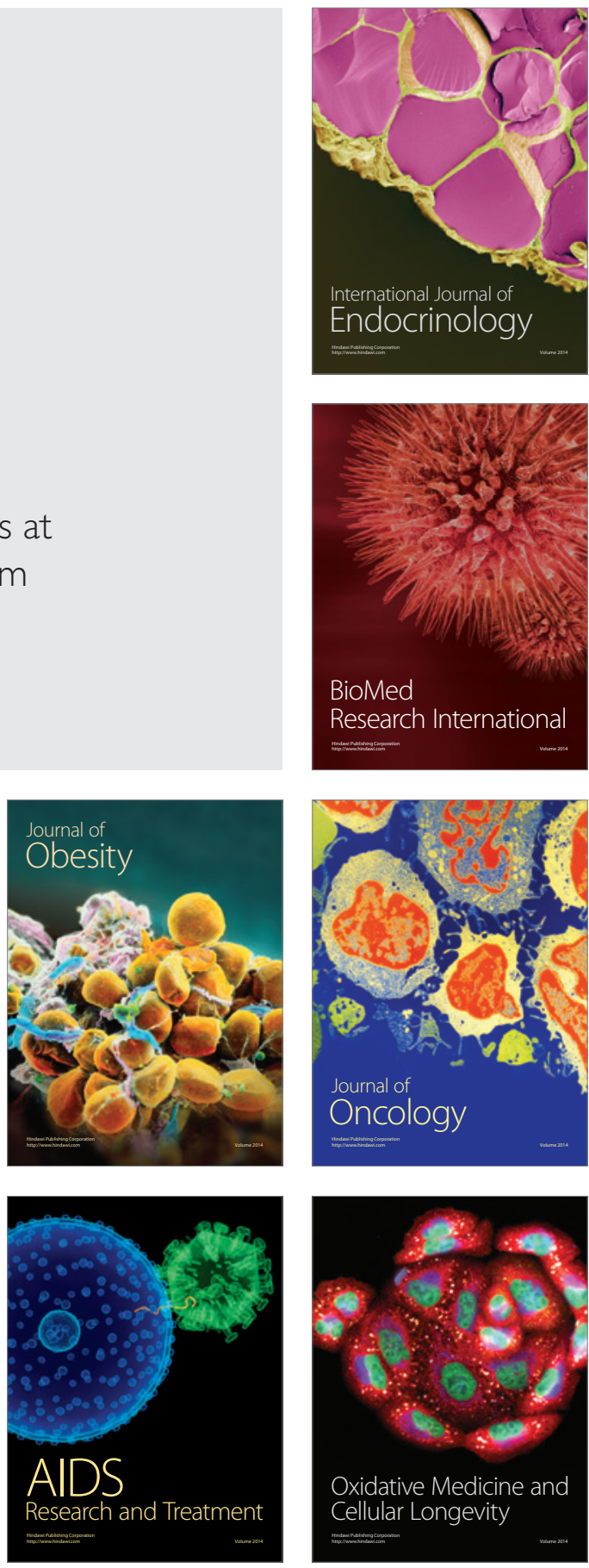